\title{
Genomic landscape of intracranial meningiomas
}

\author{
Wenya Linda Bi, MD, PhD, ${ }^{1,4}$ Malak Abedalthagafi, MD, ${ }^{2}$ Peleg Horowitz, MD, PhD, ${ }^{1}$ \\ Pankaj K. Agarwalla, MD, ${ }^{3,4}$ Yu Mei, MD, PhD, ${ }^{1}$ Ayal A. Aizer, MD, MHS, ${ }^{5}$ Ryan Brewster, BA, ${ }^{2}$ \\ Gavin P. Dunn, MD, PhD, ${ }^{6}$ Ossama Al-Mefty, MD, ${ }^{1}$ Brian M. Alexander, MD, MPH, ${ }^{5}$ \\ Sandro Santagata, MD, PhD, ${ }^{2}$ Rameen Beroukhim, MD, PhD, ${ }^{4}$ and lan F. Dunn, MD1
}

\begin{abstract}
'Department of Neurosurgery, Brigham and Women's Hospital; 2Department of Pathology, Division of Neuropathology, Brigham and Women's Hospital, ${ }^{3}$ Department of Neurosurgery, Massachusetts General Hospital; ${ }^{\circ}$ Department of Cancer Biology, DanaFarber Cancer Institute; and 5Department of Radiation Oncology, Brigham and Women's Hospital, Harvard Medical School, Boston, Massachusetts; and ${ }^{6}$ Department of Neurosurgery, Pathology, and Immunology, Center for Human Immunology and Immunotherapy Programs, Washington University School of Medicine, St. Louis, Missouri
\end{abstract}

\begin{abstract}
Meningiomas are the most common primary intracranial neoplasms in adults. Current histopathological grading schemes do not consistently predict their natural history. Classic cytogenetic studies have disclosed a progressive course of chromosomal aberrations, especially in high-grade meningiomas. Furthermore, the recent application of unbiased nextgeneration sequencing approaches has implicated several novel genes whose mutations underlie a substantial percentage of meningiomas. These insights may serve to craft a molecular taxonomy for meningiomas and highlight putative therapeutic targets in a new era of rational biology-informed precision medicine.
\end{abstract}

http://thejns.org/doi/abs/10.3171/2015.6.JNS15591

KEY WORDS meningioma; genomics; tumor classification; tumor progression; molecular taxonomy; precision medicine; targeted therapy; oncology

M ENINGIOMAS are the most common primary intracranial neoplasms in adults, accounting for $35.8 \%$ of all primary CNS tumors and more than $53 \%$ of all benign CNS tumors diagnosed in the US. ${ }^{65} \mathrm{Au}-$ topsy and imaging studies suggest an even higher prevalence, affecting almost $3 \%$ of women..$^{98}$ These lesions are believed to arise from progenitor cells that give rise to both the arachnoid cap cells of the arachnoid layer and fibroblasts that reside in the inner dura mater. ${ }^{18,45}$

The vast majority of meningiomas are indolent. ${ }^{36} \mathrm{~A}$ small percentage, however, display malignant behavior characterized by invasive growth patterns and/or markedly higher recurrence rates. Notably, even meningiomas that lack histological features of malignancy recur at significant rates. Multimodality therapy including surgery and radiation is often used in the management of these subsets of meningioma, but other therapeutic modalities have failed to improve control rates. Aggressive meningiomas and the meningiomatosis that occur in hereditary syndromes remain difficult clinical problems. Although most meningiomas are "benign," there is substantial morbidity associated with recurrence, and clinical management remains challenging for clinicians worldwide.

Unbiased genome- and exome-wide sequencing approaches have implicated a central core of gene mutations that are associated with a substantial percentage of these tumors. This information may highlight therapeutic targets and enhance biological classification of meningioma. ${ }^{12,22}$ Just as an improved understanding of genomic alterations has changed the way we classify and treat cancers including chronic myelogenous leukemia, melanoma, and lung cancer, similar interrogation of the meningioma genome has revealed potential novel treatment pathways for patients harboring these tumors. ${ }^{59}$

ABBREVIATIONS hpf = high-power field; MAPK = mitogen-activated protein kinase; $\mathrm{mTOR}=$ mammalian target of rapamycin; NF2 = neurofibromatosis Type 2; PI3K = phosphoinositide-3-kinase.

SUBMITTED March 31, 2015. ACCEPTED June 30, 2015

INCLUDE WHEN CITING Published online January 15, 2016; DOI: 10.3171/2015.6.JNS15591. 


\section{Histopathological Classification}

The current diagnostic criteria for meningiomas are largely predicated on histological features. The WHO defines 3 grades of meningiomas, with Grade II and III meningiomas associated with significantly greater rates of recurrence, morbidity, and mortality (Fig. 1) ${ }^{55}$ Grade I tumors display a broad range of morphological features and are divided into numerous histological subtypes: meningothelial, fibrous or fibroblastic, transitional (containing both meningothelial and fibroblastic components), psammomatous, angiomatous, microcystic, secretory, lymphoplasmacyte-rich, and metaplastic (Fig. 2). Patients with Grade I meningiomas have a 10 -year overall survival of $80 \%-90 \%$ and progression-free survival of approximately
$75 \%-90 \%$, with outcome influenced by extent of resection, location of tumor, and patient age..$^{77,95,96}$

Grade II (also known as atypical) meningiomas are defined by a specific set of morphological criteria and 2 distinct histological variants (clear cell and chordoid). Atypical meningiomas are defined by the presence of 4-19 mitoses per 10 microscopic hpf (40x), or the presence of 3 of 5 of the following criteria: sheetlike growth, spontaneous necrosis, high nuclear-to-cytoplasmic ratio, prominent nucleoli, and increased cellularity. Brain invasion is not included in the diagnostic paradigm of meningioma grading, but its presence implies a similar recurrence rate and risk of mortality to those found in atypical meningiomas. ${ }^{69}$ Grade II meningiomas are associated with up to 8-fold

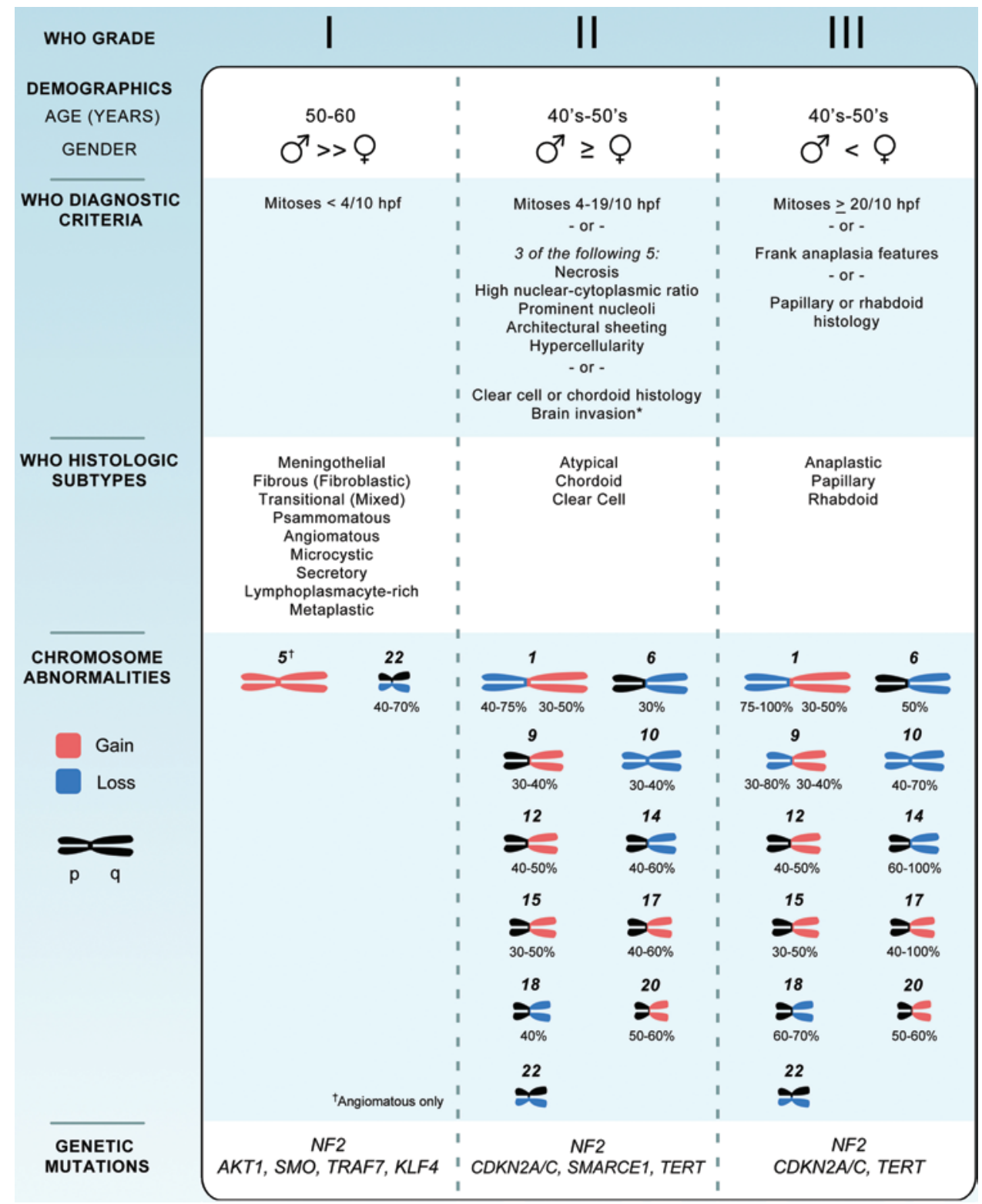

FIG. 1. Chart showing the genomic landscape of Grade I, II, and III meningiomas. Demographic data, current WHO diagnostic criteria, histological subtypes, recurrent copy number alterations, and mutations across meningiomas are shown. *Brain invasion is not formally a criterion of Grade II meningiomas, but observation of brain invasion connotes a similar risk for recurrence as in atypical meningioma. 


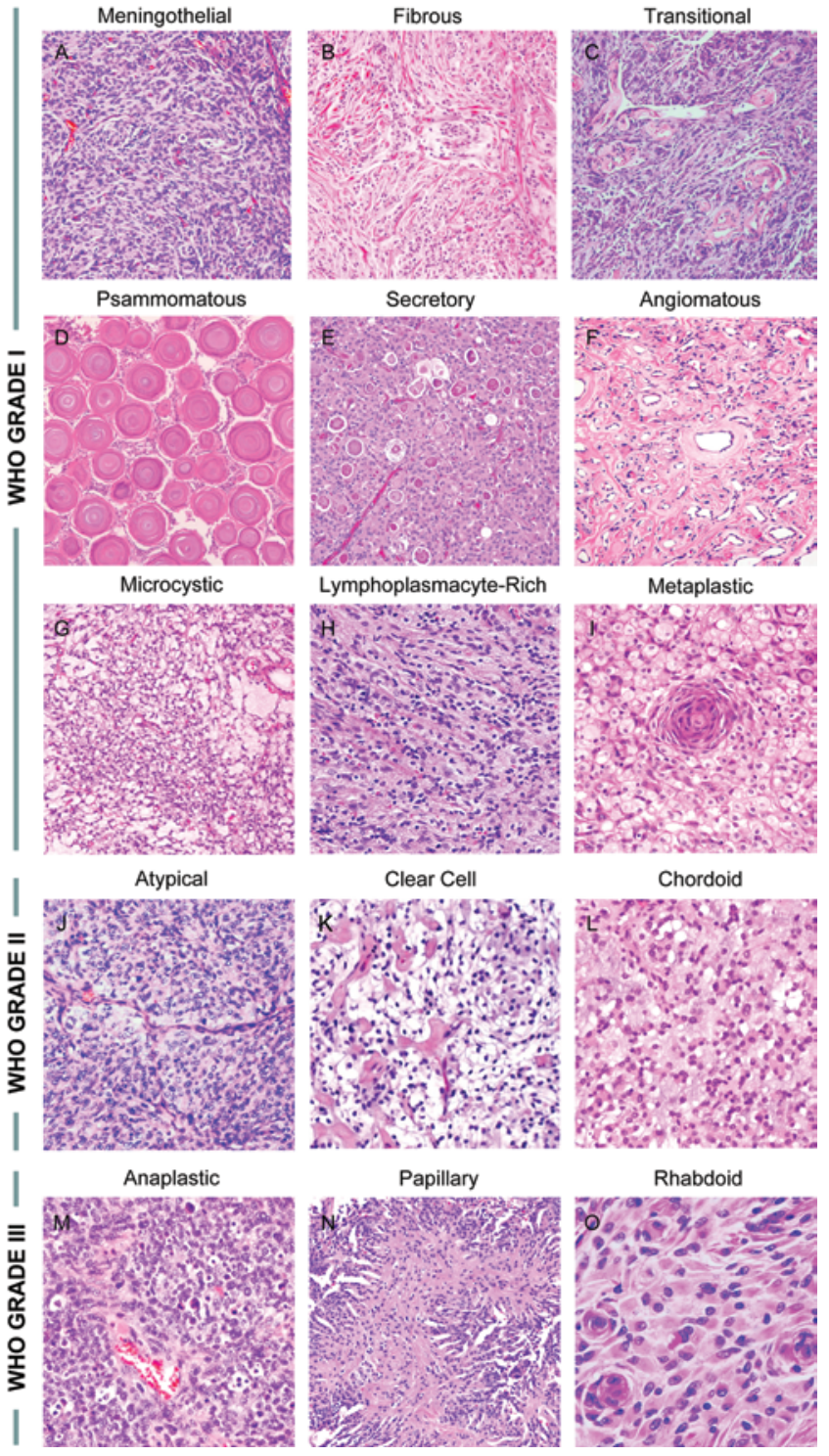

FIG. 2. Photomicrographs showing meningioma histological subtypes. Grade I tumors encompass (A) meningothelial, (B) fibrous or fibroblastic, (C) transitional, (D) psammomatous, (E) secretory, (F) angiomatous, (G) microcystic, (H) lymphoplasmacyte-rich, and (I) metaplastic subtypes. Grade II tumors include (J) atypical, (K) clear cell, and (L) chordoid meningiomas. Grade III meningiomas include (M) anaplastic, (N) papillary, and $(\mathrm{O})$ rhabdoid subtypes. $\mathrm{H} \& \mathrm{E}$, original magnification $\times 20(\mathrm{~A}-\mathrm{H}, \mathrm{J}-\mathrm{N})$, and $\times 40$ (I and $\mathrm{O})$. Images for lymphoplasmacyte-rich, metaplastic, and papillary subtypes courtesy of Dr. Arie Perry.

higher recurrence rates than Grade I meningiomas, with a 10 -year overall survival of 53\%-79\% and progression-free survival of $23 \%-78 \%$, dependent on the extent of resection and adjuvant therapies. ${ }^{28,67,92,93}$

The most aggressive types are Grade III, or anaplastic/ malignant meningiomas, and these are defined by a mitotic index of 20 or greater per $10 \mathrm{hpf}$. It can sometimes be difficult to recognize these tumors as meningiomas because they can morphologically resemble sarcoma or carcinoma. Papillary and rhabdoid histological variants are also designated as WHO Grade III. Grade III menin- giomas are associated with a 10-year overall survival of $14 \%-34 \%$ and progression-free survival of $0 \% .^{28,66}$

\section{Management Challenges in the Era of Precision Medicine}

Of the manifold challenges in the clinical management of these tumors, we highlight 2 particular areas that could be influenced by improved understanding of meningioma genomics: 1) the difficulty in accurately predicting the natural history of meningiomas based solely on histopathological grade, and 2) the lack of effective systemic medical therapies for meningiomas.

\section{Predicting Natural History Based on Tumor Grade}

Even though histological grade is helpful in prognostication of the natural history, meningiomas with low-grade histological features may recur despite adequate resection, whereas meningiomas with high-grade features may not. In these circumstances, the histological appearance of a meningioma inconsistently predicts biological behavior. Traditional histopathological definitions based on cytoarchitecture, cellularity, density of mitoses, nuclear pleomorphism, tumor necrosis, and presence of brain invasion have proved invaluable for guiding the management of patients with meningioma. However, a certain amount of subjectivity in applying standard WHO criteria and interobserver variability can confound grading. Retrospective review of meningioma grade when applying the WHO 1993, 2000, or 2007 criteria led to reclassification of up to $30 \%$ of tumors, both from lower grade to higher grade and from higher grade to lower grade. ${ }^{6,103}$ WHO Grade I meningiomas with borderline atypical features, as defined by an elevated MIB-1 proliferation index, or the presence of only 1 or 2 of the features required for a WHO Grade II designation, can also complicate counseling of patients and determining the optimal treatment strategy. Some diagnosticians may apply different thresholds when deciding on the presence of certain histological features. Tissue sampling can also lead to variability, because only representative portions of very large meningiomas are analyzed.

Histological descriptions likely do not capture all of the information necessary to understand tumor behavior. Therefore, additional molecular tools could potentially yield more reliable prognostic information as well as provide powerful additional information to better direct the optimized use of specific targeted therapeutic strategies. Molecular taxonomy has transformed the clinical management of several tumors in recent decades. Within the CNS, medulloblastomas, glioblastomas, and ependymomas provide benchmarks for integrating molecular diagnoses with subsequent decisions for adjuvant treatment and prognostication. ${ }^{13,64,101}$ Histological entities that are classically clustered together are partitioned into distinct disease subgroups, with characteristic patient demographics, genomic signatures, and clinical course. Molecular classification of meningiomas has also been proposed $;{ }^{17}$ further refinements of this concept based on a continuous variable of molecular aberrations with strong correlation to outcome are in progress, and may improve our ability to understand a patient's clinical course prospectively. 


\section{Paucity of Medical Treatments for Meningiomas}

For most meningiomas, surgery and radiation remain the mainstays of treatment. Complete resection of a Grade I meningioma including all dural attachments in the setting of observed growth, symptoms, or impending neurological deficit is frequently curative. ${ }^{86}$ However, this is not always achievable, especially with meningiomas located at the skull base and with high-grade (Grade II or III) meningiomas. Chemotherapeutic options are limited to recurrent cases that have exhausted surgical and radiation options, and these approaches have shown only limited to poor efficacy. ${ }^{100}$

Clinical trials of targeted therapeutics for meningioma to date have used agents that target classic oncogenic pathways such as vascular endothelial growth factor (VEGF), platelet-derived growth factor (PDGF), and mammalian target of rapamycin (mTOR). ${ }^{46,100}$ However, in these trials, patients are enrolled based on recurrence status but not on the presence of a definitive molecular marker that can predict response to the trial intervention. Notably, besides the long-established role for NF2 in the development of meningioma, other oncogenic drivers of meningioma development and progression have remained elusive until recently. Unlike in a number of other cancers in which targeted therapeutics can be leveraged to disable genetic aberrations that serve as the main oncogenic drivers (e.g., BRAF inhibitors for melanoma ${ }^{89}$ or cKIT inhibitors in gastrointestinal stromal tumors and chronic myelogenous leukemia ${ }^{26}$ )-the so-called "mutation-to-drug" paradigm - such approaches have not been possible in meningioma. These limitations call for better understanding of the molecular underpinnings of meningiomas and a shift toward an objective stratification for these tumors.

\section{Germline Genomic Alterations in Hereditary Meningioma Syndromes}

In patients with multiple meningiomas as a consequence of hereditary syndromes, the tumors are particularly challenging to manage. Because these syndromes often involve loss of function in key tumor suppressors, there may be reluctance to use modalities such as radiation therapy in the eventuality that this treatment leads to disease progression of targeted areas and the transformation of otherwise nontransformed normal tissue. ${ }^{7}$ Thus, detailed understanding of the biology of these conditions is critical to improving medical options for these patients.

\section{Neurofibromatosis Type 2}

Initial insight into the genetic alterations that lead to meningiomas was derived from associated familial syndromes (Table 1). The first and most thoroughly described of these syndromes is neurofibromatosis Type 2 (NF2), in which $50 \%-75 \%$ of patients develop one or more meningiomas. The underlying gene, $N F 2$, is a well-defined tumor suppressor that encodes the protein Merlin. Mutation, allelic inactivation, or loss of the tumor suppressor $N F 2$ gene and its parent chromosome 22 have been implicated in approximately $40 \%-60 \%$ of sporadic meningiomas in addition to those afflicted with neurofibromatosis. ${ }^{12,22,30,79}$ $N F 2$ probably plays an early driver role in meningioma
TABLE 1. Hereditary syndromes with meningiomas

\begin{tabular}{|c|c|c|}
\hline Syndrome & $\begin{array}{c}\text { Gene } \\
\text { Affected }\end{array}$ & $\begin{array}{c}\text { Chromosome } \\
\text { Locus }\end{array}$ \\
\hline Cowden disease & PTEN & $10 q 23.31$ \\
\hline Gardner syndrome & $A P C$ & $5 q 21-22$ \\
\hline $\begin{array}{l}\text { Gorlin (nevoid basal cell carcinoma) } \\
\text { syndrome }\end{array}$ & PTCH & $9 q 22.3$ \\
\hline Li-Fraumeni syndrome & $\begin{array}{l}\text { TP53 } \\
\text { CHEK2 }\end{array}$ & $\begin{array}{l}17 q 11.2 \\
22 q 12.1\end{array}$ \\
\hline Multiple endocrine neoplasia Type 1 & MEN & $11 q 13$ \\
\hline Multiple meningiomas \& schwannomas & SMARCB1 & $22 q 11.23$ \\
\hline Multiple spinal meningiomas & SMARCE1 & $17 q 21.2$ \\
\hline Neurofibromatosis Type 1 & NF1 & $17 q 11.2$ \\
\hline Neurofibromatosis Type 2 & NF2 & $22 q$ \\
\hline Rubinstein-Taybi syndrome & $\begin{array}{l}\text { CREBBP } \\
\text { EP300 }\end{array}$ & $\begin{array}{l}16 p 13.3 \\
22 q 13\end{array}$ \\
\hline von Hippel-Lindau syndrome & $\begin{array}{l}\text { VHL } \\
\text { CCND1 }\end{array}$ & $\begin{array}{l}3 p 26-25 \\
11 q 13\end{array}$ \\
\hline Werner syndrome & $\begin{array}{l}\text { LMNA } \\
\text { RECQL2 }\end{array}$ & $\begin{array}{l}\text { 1q21.1 } \\
8 p 12-p 11.2\end{array}$ \\
\hline Turner syndrome & - & $\mathrm{XO}$ \\
\hline
\end{tabular}

$-=$ none (purely a chromosomal abnormality).

formation, given its alteration in both low-grade and highgrade tumors ${ }^{70}$ as well as the development of meningiomas in NF2-knockout mice. ${ }^{44,45}$

Multiple hypotheses exist for the mechanism by which alterations in NF2 result in tumor formation. Merlin belongs to the protein 4.1 family, which serve to link membrane proteins to the cytoskeleton, and facilitates contact-dependent inhibition of cellular proliferation. ${ }^{24}$ Loss of Merlin activates downstream oncogenic and mitogenic pathways such as Ras/mitogen-activated protein kinase (MAPK), Notch, phosphoinositide-3-kinase (PI3K), Hippo, and mTOR, leading to uncontrolled neoplastic growth. ${ }^{34,38,39,62,78}$ In addition to dysregulation of specific signaling pathways, NF2-mutated meningiomas may also exhibit greater chromosomal instability than NF2-wild type counterparts. ${ }^{32}$ However, no targetable dependency in the NF2 pathway currently exists.

\section{Other Germline Syndromes}

Germline mutations in the Switch/Sucrose nonfermentable (SWI-SNF) chromatin-remodeling complex gene SMARCB1/INII/SNF5/hSNF5, located on chromosome 22q11, have been identified in several families with multiple meningiomas and schwannomas ${ }^{5,21,97}$ but appear to be only one of many contributors in the full spectrum of patients with multiple meningiomas. ${ }^{33}$ Interestingly, mutation or loss of the SWI/SNF-related, matrix-associated, actin-dependent regulator of chromatin subfamily B member 1 (SMARCB1) is a signature of tumors with rhabdoid morphology, including malignant rhabdoid tumors (MRT) and atypical teratoid/rhabdoid tumors (ATRT), ${ }^{37,50}$ and results in persistent activation of the AKT oncogenic signaling pathway. ${ }^{25}$ This raises the question of whether 
alterations in SMARCB1 might also contribute to tumorigenesis in sporadic rhabdoid meningiomas.

Mutations in another member of the SWI-SNF family, SMARCE1, have been noted in families with multiple spinal meningiomas as well as several cases of cranial meningiomas. ${ }^{87,88}$ This familial syndrome occurs in the absence of schwannomas and is transmitted with autosomal dominant inheritance. In patients with germline SMARCE1 aberrations, chromosome 22 and NF2 appear to be normal.

Other familial syndromes involving meningiomas include neurofibromatosis Type 1 (NF1, 17q11.2); Cowden disease (PTEN, 10q23.31); Gorlin or nevoid basal cell carcinoma syndrome (PTCH, 9q22.3); Li-Fraumeni syndrome (TP53, 17q11.2; CHEK2, 22q12.1); Gardner syndrome (APC, 5q21-22); Rubinstein-Taybi syndrome (CREBBP, 16p13.3; EP300, 22q13); von Hippel-Lindau syndrome (VHL, 3p26-25; CCND1/cyclin D1, 11q13); Werner syndrome (LMNA, 1q21.1; RECQL2, 8p12-p11.2); and multiple endocrine neoplasia Type $1(M E N, 11 \mathrm{q} 13) \cdot{ }^{84}$ Multiple meningiomas have been observed in patients with mutations in $C C M 3 / P D C D 10$, a gene associated with cerebral cavernous malformations that contributes to proliferation and resistance to apoptosis via activation of AKT signaling, ${ }^{20,48,56,75}$ and the $S U F U$ gene, which regulates hedgehog signaling. ${ }^{1}$ Taken together, the multitude of familial syndromes associated with meningiomas suggests that many diverse mechanisms may lead to the proliferation and growth of meningioma. Further study into how each of these genetic lesions predisposes patients to tumor formation will be critical to optimization of medical strategies as well as enhancement of our biological insight into these syndromes.

\section{Somatic Genomic Alterations in Meningiomas}

Although meningiomas that arise in hereditary syndromes may offer mechanistic insights, the majority of meningiomas arise sporadically. Over the last several years, the application of genomic approaches has given us a high-resolution picture of the types of somatic alterations - at both the level of copy number and of single-nucleotide changes - that underlie these tumor types and set the stage for novel clinical trials.

\section{Chromosomal Copy Number Alterations}

Cytogenetic studies shed early insight into chromosomal-level alterations in meningiomas. The most common alteration observed in Grade I meningiomas is monosomy of chromosome 22, which is observed in $40 \%-70 \%$ of cases.$^{69}$ Aside from this recurrent copy number alteration, the copy number landscape of Grade I tumors is typically balanced. One exception is the angiomatous subtype of benign meningiomas, which harbors multiple polysomies across the genome, most commonly of chromosome $5 .^{2}$ Atypical and anaplastic meningiomas express frequent loss of chromosomes 1p, 6q, 10,14q, and 18q, as well as gain of chromosomes 1q, 9q, 12q, 15q, 17q, and 20q (Fig. 1), with a propensity for increased genomic aberrations with higher grade..$^{15,16,69}$
Recurrent chromosomal gains and losses have prompted investigation into candidate driver genes within these regions. The losses of chromosomes $1 p$ and $14 \mathrm{q}$ are the next 2 most frequent cytogenetic abnormalities observed in meningiomas (after chromosome 22 loss), affecting half of Grade II and nearly all Grade III meningiomas. ${ }^{16}$ Investigations of an array of candidate driver genes on chromosome 1p, including TP $73,{ }^{54} C D K N 2 C,{ }^{11} R A D 54,{ }^{60}$ $E P B 41,{ }^{72} G A D D 45 A,{ }^{72}$ and $A L P L,{ }^{63}$ have yet to provide concrete evidence for a consistent role in meningioma tumorigenesis. Similarly, malignant meningiomas have decreased expression of several tumor suppressor genes on chromosome $14 \mathrm{q}$, such as $N D R G 2^{57}$ and the noncoding RNA $M E G 3,{ }^{104}$ but rarely have direct mutations in these candidates. One possible mechanism leading to reduced gene expression, in the absence of inactivating mutations, is silencing through methylation. ${ }^{8,52,53,57}$ The identification of somatic mutations in SMARCBI and in the histone demethylases $K D M 5 C$ and $K D M 6 A$ in Grade I meningiomas suggests a role for epigenetic modification driving tumor inception. ${ }^{12}$

Aberrations in chromosome 9p may disrupt cell cycle regulation due to the location of several important cell cycle genes on 9p21, including $C D K N 2 A, C D K N 2 B$, and $A R F .{ }^{11} \mathrm{INK} 4 \mathrm{a} / \mathrm{p} 16$ (encoded by $C D K N 2 A$ ) and INK4b/ p18 (encoded by $C D K N 2 B$ ) inhibit the cyclin-dependent kinases CDK4 and CDK6, respectively, whereas ARF/p14 promotes $\mathrm{p} 53$ activity through repression of its inhibitor, the murine double minute 2 (MDM2) protein. ${ }^{91}$ Frequent deletions or inactivating mutations in these cell cycle regulators are found in anaplastic meningiomas, and correlate with shorter survival. ${ }^{68}$

Loss of chromosome 10 is frequently observed in multiple cancers, including high-grade meningiomas. However, alterations in the influential tumor suppressor PTEN are not regularly observed in meningiomas. ${ }^{10,71}$ Credible driver genes underlying chromosome $17 \mathrm{q}$ amplifications and $18 \mathrm{p}$ losses in malignant meningiomas have yet to be identified..$^{14,15}$

\section{Chromosome 22 Mutation Candidates}

$N F 2$ remains the most commonly altered genetic locus across all meningiomas. ${ }^{12,22,35,61}$ In some tumors, one allele harbors an NF2 mutation while the other harbors NF2 copy loss, resulting in a double hit. Meningiomas with broad-range loss in chromosome 22 and preserved expression of wild-type $N F 2$ suggested the presence of adjacent genes on chromosome $22 \mathrm{q}$ that may also play a role in tumorigenesis. Potential candidate genes on chromosome 22 that could contribute to the pathogenesis of meningioma include SMARCB1, ${ }^{82}$ checkpoint kinase 2 (CHEK2), ${ }^{102}$ and clathrin heavy chain polypeptide gene (CLH-22/CTCL1).

Somatic mutations and loss of SMARCB1, in addition to the germline mutations previously discussed, have been reported in sporadic meningiomas, highlighting a growing recognition of epigenetic modifiers in a number of diverse and molecularly distinct cancer types. ${ }^{12}$ Similarly, isolated mutations of CHEK2 have been noted in meningiomas, ${ }^{12}$ in addition to frequent codeletion with $N F 2$ given their proximity on 22q12.2. ${ }^{102}$ CHEK2 contributes to homologous and nonhomologous mechanisms of DNA repair and 
is postulated to serve as a tumor suppressor during cell cycle progression. Frequent loss of expression and rare rearrangement is also seen across meningiomas with the CLH-22 gene, located on 22q11, but its functional role remains to be elucidated.

\section{Somatic Mutations Revealed by Next-Generation Sequencing Approaches}

In the last 3 years, the use of next-generation DNA sequencing has yielded new insights into recurrent mutations that occur in meningiomas. Specifically, recurrent somatic mutations in 4 genes were identified. ${ }^{12,22}$ These mutated genes include the classic proto-oncogene v-Akt murine thymoma viral oncogene homolog 1 (AKT1), the Hedgehog pathway signaling member smoothened (SMO), the proapoptotic E3 ubiquitin ligase TNF receptor-associated factor 7 (TRAF7), and the pluripotency transcription factor Kruppel-like factor 4 (KLF4). Collectively, these mutations are present in up to $40 \%$ of sporadic meningiomas, appear preferentially in tumors at the skull base, and almost always occur without associated NF2 mutation or chromosome 22 loss (Fig. 3).

Mutations in TRAF7, located on chromosome 16p13, are observed in $12 \%-25 \%$ of meningiomas. ${ }^{22} \mathrm{~A}$ majority of meningiomas with TRAF7 mutations also harbor mutations in AKT1 or KLF4 mutations, but not both. ${ }^{22,74}$ However, TRAF7 mutations occur in a mostly mutually exclusive fashion with $S M O$ mutations, $N F 2$ mutations, and chromosome 22 loss. ${ }^{22}$ The mechanism and downstream effectors of this mutation remain to be discovered.
A subset of TRAF7-mutated tumors harbor the $A K T 1^{\mathrm{E} 17 \mathrm{~K}}$ mutation, which is observed in $6.8 \%$ of meningiomas..$^{22,80}$ $A K T 1$, located on chromosome $14 \mathrm{q} 32$, is mutated at low frequency in a range of cancers including carcinoma of the breast, lung, and colon. ${ }^{9}$ In meningioma, recurrent $A K T 1$ mutations produce a known oncogenic alteration of glutamic acid to lysine at codon 17 (E17K), and appear exclusive of $N F 2, K L F 4$, and SMO mutations..$^{22}$ The $A K T l^{\mathrm{E} 17 \mathrm{~K}}$ mutation results in activation of downstream effectors of the PI3K/AKT/mTOR oncogenic pathway, rendering it a potential target by selective AKT inhibitors, several of which are currently in Phase I and II clinical testing for the treatment of a broad range of cancers.

Similarly, SMO mutations result in downstream activation of Hedgehog signaling, another well-characterized pathway in cancer that is notably dysregulated in basal cell carcinoma and medulloblastoma. ${ }^{43,73}$ In basal cell carcinoma, where more than $90 \%$ of tumors have mutations in either SMO or PTCH, inhibition of SMO has been particularly effective in the setting of locally advanced or metastatic disease, with vismodegib receiving FDA approval in early $2012 .{ }^{83}$ SMO mutations are observed in approximately $5.5 \%$ of Grade I meningiomas, or in greater than $10 \%$ of non-NF2-altered tumors. ${ }^{12,22}$

Last, KLF4, located on chromosome 9q 31 , is a transcription factor that promotes reprogramming of differentiated somatic cells back to a pluripotent state.$^{94} \mathrm{~A}$ recurrent mutation in $K L F 4^{K 409 Q}$ results in a lysine-to-glutamine substitution at codon 409 (K409Q), and is observed in $15.7 \%$ of Grade I meningiomas. KLF mutations co-oc-

A

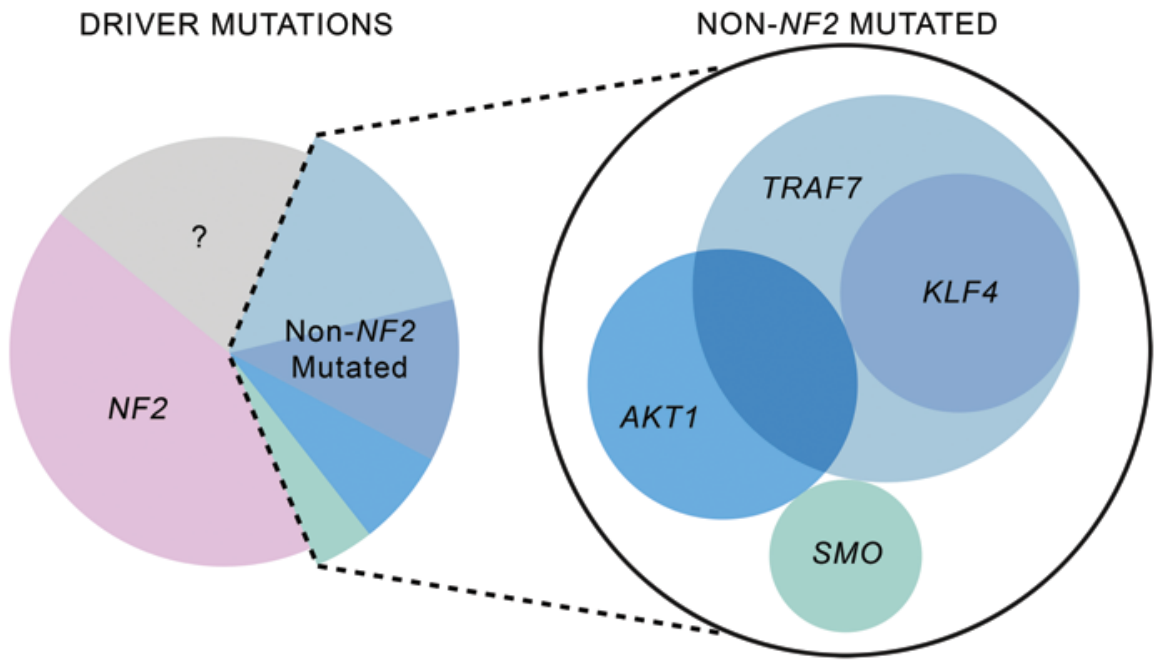

B

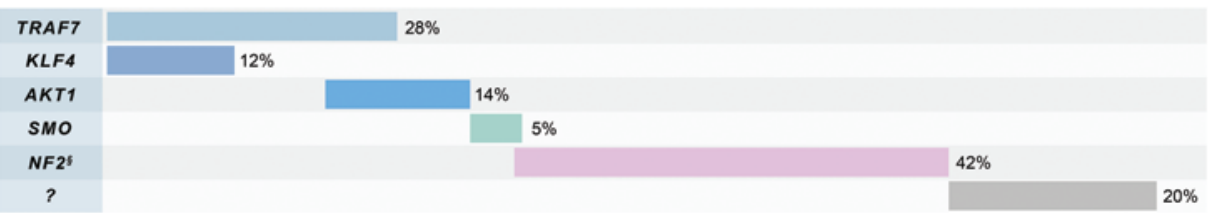

FIG. 3. Charts showing distribution of NF2, AKT1, SMO, TRAF7, and KLF4 mutations in Grade I meningiomas. A: Recurrent oncogenic driver mutations in Grade I meningiomas include TRAF7, AKT1, KLF4, and SMO, which largely occur in a mutually exclusive pattern with NF2. Mutations in KLF4 and AKT1 overlap with TRAF7, in proportion to the areas represented in the Venn diagram. B: Distribution of TRAF7, AKT1, KLF4, SMO, and NF2 mutations across Grade I meningiomas. Recurrent oncogenic changes remain unclear for approximately $20 \%$ of meningiomas (designated by the question mark). NF2 mutation or loss is designated by the section symbol. Data aggregated from Brastianos and Horowitz et al. and from Clark et al. 
cur with TRAF7 mutations and are exclusive of $N F 2$ and $A K T 1$ mutations. ${ }^{22}$ Alteration of this pluripotent transcription factor may represent a recapitulation of embryological mechanisms to drive tumor formation.

\section{Genotype-Phenotype Associations in Meningioma}

The genetic makeup of meningiomas is increasingly recognized to produce characteristic phenotypes. In the case of $N F 2$, inactivation of this gene is observed in $70 \%-80 \%$ of fibroblastic and transitional meningiomas, but less than $1 \%$ of secretory meningiomas. This profound difference in mutation frequency suggests that some morphological subtypes of meningioma harbor subtype-specific oncogenic mutations other than $N F 2$, which was corroborated by the discovery of mutations in $A K T 1, S M O$, TRAF7, and KLF4 (Table 2).

\section{Genetic Hallmarks of Meningioma Subtypes}

Nearly all cases of secretory meningioma harbor mutations in both $K L F 4^{K 409 Q}$ and TRAF7 but lack mutations in NF2. ${ }^{74}$ The KLF4 mutation has not been observed in any other nonsecretory meningiomas, CNS tumors, or systemic malignancies. TRAF7 mutations overlap with $K L F 4$ mutations but are found in a larger spectrum of meningioma subtypes, ${ }^{22}$ including $97 \%$ of secretory meningiomas and $8 \%$ of nonsecretory meningiomas. ${ }^{74}$ AKT1 mutations, in contrast, are common in Grade I meningothelial meningiomas and increasingly rare with progressively higher grades of malignancy. ${ }^{80}$

Clear cell meningiomas, in the hereditary multiple spinal meningioma syndrome and some cranial locations, are associated with loss-of-function mutations in SMARCE1. ${ }^{87,88}$ The role of this mutation in sporadic clear cell meningiomas merits further validation.

In addition to mutation signatures of meningioma subtypes, angiomatous meningiomas have been reported to harbor a unique profile of multiple chromosomal polysomies, most frequently of chromosome $5 .^{2}$ An unbalanced translocation between chromosomes 1 and 3 has also been proposed as a marker of chordoid meningiomas. ${ }^{90}$ The concept of subtype-specific genomic alterations points to a potential molecular taxonomy for meningiomas in the future.

\section{Location-Specific Genetic Signatures}

Specific genetic alterations not only associate with histopathological subtypes, they also correlate with the dis-

TABLE 2. Meningioma subtype-specific genetic alterations

\begin{tabular}{lll}
\multicolumn{1}{c}{ Subtype } & \multicolumn{1}{c}{$\begin{array}{c}\text { Associated Genetic } \\
\text { Alteration }\end{array}$} & \multicolumn{1}{c}{ Inheritance } \\
\hline Meningothelial & AKT1(E17K) & Sporadic \\
\hline Fibroblastic, transitional & NF2 & Sporadic, familial \\
\hline Secretory & KLF4(K409Q), TRAF7 & Sporadic \\
\hline Angiomatous & Polysomy 5 & Sporadic \\
\hline Clear cell & SMARCE1 & Familial \\
\hline Chordoid & $\begin{array}{c}\text { der(1)t(1;3)(p12-13;q11) } \\
\text { translocation }\end{array}$ & Sporadic \\
& & \\
\hline
\end{tabular}

tribution of tumors. Convexity meningiomas more often harbor mutations in NF2 and chromosome 22 loss of heterozygosity, and belong to the fibroblastic and transitional subtypes. In contrast, meningiomas along the anterior cranial base typically retain chromosome $22 \mathrm{q}$ heterozygosity and are more likely to express mutations in SMO or AKTI/ TRAF7.12,22 This concurs with observations that cranial base meningiomas are predominantly of the meningothelial subtype, because $A K T 1$ mutations are largely found in meningothelial meningiomas..$^{12,47}$

\section{Genetic Basis of High-Grade Meningiomas}

One fundamental question that remains unanswered is whether high-grade meningiomas result from transformation of a low-grade precursor through acquisition of additional oncogenic drivers, or as de novo malignant tumors. Clinical experience and cytogenetic studies suggest that distinct primary de novo and secondary transformation pathways exist that result in high-grade meningiomas, each with a molecular signature, akin to the pattern observed in glioblastoma multiforme. ${ }^{3,99}$

In one series of recurrent meningiomas with documented histopathological progression, a similar pattern of chromosome $22,1 \mathrm{p}$, and $14 \mathrm{q}$ loss existed in both Grade I and Grade II-III recurrences. ${ }^{3}$ Other studies have identified progressive loss of chromosomes 1p, 6q, 9p, 10, 14q, $18 \mathrm{q}$, and $19 \mathrm{q}$ in atypical and anaplastic meningiomas as compared with benign Grade I meningiomas (Fig. 1). ${ }^{99}$ In addition, high-grade meningiomas are associated with gains of 1q, 9q, 12q, 15q, 17q, and 20q. Anaplastic meningiomas in particular have frequent loss of chromosome $9 p$ and amplification of $17 q 23 .^{76}$ The acquisition of these changes over time suggests underlying chromosomal instability with progressive meningioma grade. Such instability could be innate to an oncogenic driver within the incipient tumor or induced by external factors. . $^{3,4,29}$

Despite the recognition of recurrent chromosomal changes in malignant progression of meningiomas, underlying gene targets that may be driving such changes largely remain elusive. It may be that gains and losses of specific chromosomal arms reflect a more pervasive underlying genomic instability, resulting from the convergence of several aberrant signaling pathways. Another innate source of genomic instability relates to progressive lengthening of telomeres. ${ }^{19,49,51,81,85}$ Telomerase activation has been demonstrated in $10 \%$ of Grade I, 50\% of Grade II, and $95 \%$ of Grade III meningiomas. Interestingly, mutations of the telomerase reverse transcriptase (TERT) gene promoter that result in increased expression of TERT mRNA are associated with meningiomas that relapse, with the highest frequency of TERT promoter mutations (28\%) present in relapsing meningioma that have undergone histological progression. ${ }^{31}$

In summary, the genetic mutations and chromosomal aneuploidy found in meningiomas implicate a critical role for cell cycle disruption, the hedgehog (Hh) pathway, and the PI3K/Akt pathway in tumorigenesis. Gene expression studies and cell line models further suggest activation of MAPK, Notch, and growth factor autocrine loops in meningiomas. ${ }^{23,40-42,58}$ Aside from mechanisms that promote 
uncontrolled proliferation, malignant meningioma may also usurp the telomerase clock to escape senescence and possibly immunomodulate the meningioma's microenvironment. ${ }^{27}$ Greater insight into recurrent drivers underlying malignant transformation may be acquired through future genomic studies.

\section{Conclusions}

The study of meningioma is undergoing a renaissance due to the application of multiplatform molecular, genomic, and epigenetic profiling. These large-scale, systematic approaches inform a molecular taxonomy that promises to influence diagnosis, disease classification, and, ultimately, clinical management; indeed, the mutational and copy number profiles of meningiomas are increasingly appreciated to predict anatomical location, histological phenotype, and clinical outcome, offering profound implications for adjuvant therapy options and patient counseling.

Further understanding of the factors that drive meningioma development and progression will lead to the classification of every patient's tumor according to its signature alterations, ushering in an era in which meningiomas will be considered in the same light as other tumors whose molecular underpinnings have fueled the nascent precisionmedicine age.

\section{Acknowledgments}

We thank Dr. Arie Perry for the generous contribution of immunohistochemical images.

\section{References}

1. Aavikko M, Li SP, Saarinen S, Alhopuro P, Kaasinen E, Morgunova E, et al: Loss of SUFU function in familial multiple meningioma. Am J Hum Genet 91:520-526, 2012

2. Abedalthagafi MS, Merrill PH, Bi WL, Jones RT, Listewnik ML, Ramkissoon SH, et al: Angiomatous meningiomas have a distinct genetic profile with multiple chromosomal polysomies including polysomy of chromosome 5 . Oncotarget 5:10596-10606, 2014

3. Al-Mefty O, Kadri PA, Pravdenkova S, Sawyer JR, Stangeby C, Husain M: Malignant progression in meningioma: documentation of a series and analysis of cytogenetic findings. J Neurosurg 101:210-218, 2004

4. Al-Mefty O, Topsakal C, Pravdenkova S, Sawyer JR, Harrison MJ: Radiation-induced meningiomas: clinical, pathological, cytokinetic, and cytogenetic characteristics. J Neurosurg 100:1002-1013, 2004

5. Bacci C, Sestini R, Provenzano A, Paganini I, Mancini I, Porfirio B, et al: Schwannomatosis associated with multiple meningiomas due to a familial SMARCB1 mutation. Neurogenetics 11:73-80, 2010

6. Backer-Grøndahl T, Moen BH, Torp SH: The histopathological spectrum of human meningiomas. Int J Clin Exp Pathol 5:231-242, 2012

7. Baser ME, Evans DG, Jackler RK, Sujansky E, Rubenstein A: Neurofibromatosis 2, radiosurgery and malignant nervous system tumours. Br J Cancer 82:998, 2000 (Letter)

8. Bello MJ, Amiñoso C, Lopez-Marin I, Arjona D, GonzalezGomez P, Alonso ME, et al: DNA methylation of multiple promoter-associated $\mathrm{CpG}$ islands in meningiomas: relationship with the allelic status at $1 p$ and 22q. Acta Neuropathol 108:413-421, 2004

9. Bleeker FE, Felicioni L, Buttitta F, Lamba S, Cardone L,
Rodolfo M, et al: AKT1(E17K) in human solid tumours Oncogene 27:5648-5650, 2008

10. Boström J, Cobbers JM, Wolter M, Tabatabai G, Weber RG, Lichter P, et al: Mutation of the PTEN (MMAC1) tumor suppressor gene in a subset of glioblastomas but not in meningiomas with loss of chromosome arm 10q. Cancer Res 58:29-33, 1998

11. Boström J, Meyer-Puttlitz B, Wolter M, Blaschke B, Weber RG, Lichter P, et al: Alterations of the tumor suppressor genes CDKN2A (p16(INK4a)), p14(ARF), CDKN2B (p15(INK4b)), and CDKN2C (p18(INK4c)) in atypical and anaplastic meningiomas. Am J Pathol 159:661-669, 2001

12. Brastianos PK, Horowitz PM, Santagata S, Jones RT, McKenna A, Getz G, et al: Genomic sequencing of meningiomas identifies oncogenic SMO and AKT1 mutations. Nat Genet 45:285-289, 2013

13. Brennan CW, Verhaak RG, McKenna A, Campos B, Noushmehr H, Salama SR, et al: The somatic genomic landscape of glioblastoma. Cell 155:462-477, 2013

14. Büschges R, Boström J, Wolter M, Blaschke B, Weber RG, Lichter P, et al: Analysis of human meningiomas for aberrations of the MADH2, MADH4, APM-1 and DCC tumor suppressor genes on the long arm of chromosome 18. Int J Cancer 92:551-554, 2001

15. Büschges R, Ichimura K, Weber RG, Reifenberger G, Collins VP: Allelic gain and amplification on the long arm of chromosome 17 in anaplastic meningiomas. Brain Pathol 12:145-153, 2002

16. Cai DX, Banerjee R, Scheithauer BW, Lohse CM, Kleinschmidt-Demasters BK, Perry A: Chromosome 1p and $14 \mathrm{q}$ FISH analysis in clinicopathologic subsets of meningioma: diagnostic and prognostic implications. J Neuropathol Exp Neurol 60:628-636, 2001

17. Carvalho LH, Smirnov I, Baia GS, Modrusan Z, Smith JS, Jun P, et al: Molecular signatures define two main classes of meningiomas. Mol Cancer 6:64, 2007

18. Castellano F, Ruggiero G: Meningiomas of the posterior fossa. Acta Radiol Suppl 104:1-177, 1953

19. Chen HJ, Liang CL, Lu K, Lin JW, Cho CL: Implication of telomerase activity and alternations of telomere length in the histologic characteristics of intracranial meningiomas. Cancer 89:2092-2098, 2000

20. Chen L, Tanriover G, Yano H, Friedlander R, Louvi A, Gunel M: Apoptotic functions of PDCD10/CCM3, the gene mutated in cerebral cavernous malformation 3. Stroke 40:1474-1481, 2009

21. Christiaans I, Kenter SB, Brink HC, van Os TA, Baas F, van den Munckhof P, et al: Germline SMARCB1 mutation and somatic NF2 mutations in familial multiple meningiomas. J Med Genet 48:93-97, 2011

22. Clark VE, Erson-Omay EZ, Serin A, Yin J, Cotney J, Ozduman K, et al: Genomic analysis of non-NF2 meningiomas reveals mutations in TRAF7, KLF4, AKT1, and SMO. Science 339: 1077-1080, 2013

23. Cuevas IC, Slocum AL, Jun P, Costello JF, Bollen AW, Riggins GJ, et al: Meningioma transcript profiles reveal deregulated Notch signaling pathway. Cancer Res 65:5070-5075, 2005

24. Curto M, McClatchey AI: Nf2/Merlin: a coordinator of receptor signalling and intercellular contact. Br J Cancer 98:256-262, 2008

25. Darr J, Klochendler A, Isaac S, Eden A: Loss of IGFBP7 expression and persistent AKT activation contribute to SMARCB1/Snf5-mediated tumorigenesis. Oncogene 33:3024-3032, 2014

26. Druker BJ, Talpaz M, Resta DJ, Peng B, Buchdunger E, Ford JM, et al: Efficacy and safety of a specific inhibitor of the BCR-ABL tyrosine kinase in chronic myeloid leukemia. N Engl J Med 344:1031-1037, 2001 
27. Du Z, Abedalthagafi M, Aizer AA, McHenry AR, Sun HH, Bray MA, et al: Increased expression of the immune modulatory molecule PD-L1 (CD274) in anaplastic meningioma. Oncotarget 6:4704-4716, 2015

28. Durand A, Labrousse F, Jouvet A, Bauchet L, Kalamaridès M, Menei P, et al: WHO grade II and III meningiomas: a study of prognostic factors. J Neurooncol 95:367-375, 2009

29. Durant ST, Paffett KS, Shrivastav M, Timmins GS, Morgan WF, Nickoloff JA: UV radiation induces delayed hyperrecombination associated with hypermutation in human cells. Mol Cell Biol 26:6047-6055, 2006

30. Fontaine B, Rouleau GA, Seizinger BR, Menon AG, Jewell AF, Martuza RL, et al: Molecular genetics of neurofibromatosis 2 and related tumors (acoustic neuroma and meningioma). Ann N Y Acad Sci 615:338-343, 1991

31. Goutagny S, Nault JC, Mallet M, Henin D, Rossi JZ, Kalamarides M: High incidence of activating TERT promoter mutations in meningiomas undergoing malignant progression. Brain Pathol 24:184-189, 2014

32. Goutagny S, Yang HW, Zucman-Rossi J, Chan J, Dreyfuss JM, Park PJ, et al: Genomic profiling reveals alternative genetic pathways of meningioma malignant progression dependent on the underlying NF2 status. Clin Cancer Res 16:4155-4164, 2010

33. Hadfield KD, Smith MJ, Trump D, Newman WG, Evans DG: SMARCB1 mutations are not a common cause of multiple meningiomas. J Med Genet 47:567-568, 2010

34. Hamaratoglu F, Willecke M, Kango-Singh M, Nolo R, Hyun E, Tao C, et al: The tumour-suppressor genes NF2/ Merlin and Expanded act through Hippo signalling to regulate cell proliferation and apoptosis. Nat Cell Biol 8:27-36, 2006

35. Harada T, Irving RM, Xuereb JH, Barton DE, Hardy DG, Moffat DA, et al: Molecular genetic investigation of the neurofibromatosis type 2 tumor suppressor gene in sporadic meningioma. J Neurosurg 84:847-851, 1996

36. Herscovici Z, Rappaport Z, Sulkes J, Danaila L, Rubin G: Natural history of conservatively treated meningiomas. Neurology 63:1133-1134, 2004

37. Hollmann TJ, Hornick JL: INI1-deficient tumors: diagnostic features and molecular genetics. Am J Surg Pathol 35:e47-e63, 2011

38. James MF, Han S, Polizzano C, Plotkin SR, Manning BD, Stemmer-Rachamimov AO, et al: NF2/merlin is a novel negative regulator of mTOR complex 1 , and activation of mTORC1 is associated with meningioma and schwannoma growth. Mol Cell Biol 29:4250-4261, 2009

39. James MF, Stivison E, Beauchamp R, Han S, Li H, Wallace MR, et al: Regulation of mTOR complex 2 signaling in neurofibromatosis 2-deficient target cell types. Mol Cancer Res 10:649-659, 2012

40. Johnson MD, O'Connell MJ, Pilcher W, Reeder JE: Fibroblast growth factor receptor-3 expression in meningiomas with stimulation of proliferation by the phosphoinositide 3 kinase-Akt pathway. J Neurosurg 112:934-939, 2010

41. Johnson MD, Okediji E, Woodard A: Transforming growth factor-beta effects on meningioma cell proliferation and signal transduction pathways. J Neurooncol 66:9-16, 2004

42. Johnson MD, Woodard A, Kim P, Frexes-Steed M: Evidence for mitogen-associated protein kinase activation and transduction of mitogenic signals by platelet-derived growth factor in human meningioma cells. J Neurosurg 94:293-300, 2001

43. Jones DT, Jäger N, Kool M, Zichner T, Hutter B, Sultan M, et al: Dissecting the genomic complexity underlying medulloblastoma. Nature 488:100-105, 2012

44. Kalamarides M, Niwa-Kawakita M, Leblois H, Abramowski $\mathrm{V}$, Perricaudet M, Janin A, et al: Nf2 gene inactivation in arachnoidal cells is rate-limiting for meningioma development in the mouse. Genes Dev 16:1060-1065, 2002

45. Kalamarides M, Stemmer-Rachamimov AO, NiwaKawakita M, Chareyre F, Taranchon E, Han ZY, et al: Identification of a progenitor cell of origin capable of generating diverse meningioma histological subtypes. Oncogene 30:2333-2344, 2011

46. Kaley T, Barani I, Chamberlain M, McDermott M, Panageas K, Raizer J, et al: Historical benchmarks for medical therapy trials in surgery- and radiation-refractory meningioma: a RANO review. Neuro Oncol 16:829-840, 2014

47. Kros J, de Greve K, van Tilborg A, Hop W, Pieterman H, Avezaat C, et al: NF2 status of meningiomas is associated with tumour localization and histology. J Pathol 194:367372,2001

48. Labauge P, Fontaine B, Neau JP, Bergametti F, Riant F, Blecon A, et al: Multiple dural lesions mimicking meningiomas in patients with CCM3/PDCD10 mutations. Neurology 72:2044-2046, 2009

49. Langford LA, Piatyszek MA, Xu R, Schold SC Jr, Wright WE, Shay JW: Telomerase activity in ordinary meningiomas predicts poor outcome. Hum Pathol 28:416-420, 1997

50. Lawrence MS, Stojanov P, Mermel CH, Robinson JT, Garraway LA, Golub TR, et al: Discovery and saturation analysis of cancer genes across 21 tumour types. Nature 505:495-501, 2014

51. Leuraud P, Dezamis E, Aguirre-Cruz L, Taillibert S, Lejeune J, Robin E, et al: Prognostic value of allelic losses and telomerase activity in meningiomas. J Neurosurg 100:303-309, 2004

52. Liu Y, Pang JC, Dong S, Mao B, Poon WS, Ng HK: Aberrant $\mathrm{CpG}$ island hypermethylation profile is associated with atypical and anaplastic meningiomas. Hum Pathol 36:416-425, 2005

53. Lomas J, Amiñoso C, Gonzalez-Gomez P, Eva Alonso M, Arjona D, Lopez-Marin I, et al: Methylation status of TP73 in meningiomas. Cancer Genet Cytogenet 148:148-151, 2004

54. Lomas J, Bello MJ, Arjona D, Gonzalez-Gomez P, Alonso ME, de Campos JM, et al: Analysis of p73 gene in meningiomas with deletion at $1 \mathrm{p}$. Cancer Genet Cytogenet 129:88-91, 2001

55. Louis DN, Ohgaki H, Wiestler OD, Cavenee WK, Burger PC, Jouvet A, et al (eds): WHO Classification of Tumours of the Central Nervous System, ed 4. Lyon, France: IARC, 2007

56. Louvi A, Chen L, Two AM, Zhang H, Min W, Günel M: Loss of cerebral cavernous malformation $3(\mathrm{Ccm} 3)$ in neuroglia leads to CCM and vascular pathology. Proc Natl Acad Sci U S A 108:3737-3742, 2011

57. Lusis EA, Watson MA, Chicoine MR, Lyman M, Roerig P, Reifenberger G, et al: Integrative genomic analysis identifies NDRG2 as a candidate tumor suppressor gene frequently inactivated in clinically aggressive meningioma. Cancer Res 65:7121-7126, 2005

58. Mawrin C, Sasse T, Kirches E, Kropf S, Schneider T, Grimm C, et al: Different activation of mitogen-activated protein kinase and Akt signaling is associated with aggressive phenotype of human meningiomas. Clin Cancer Res 11:4074-4082, 2005

59. McDermott U, Downing JR, Stratton MR: Genomics and the continuum of cancer care. N Engl J Med 364:340-350, 2011

60. Mendiola M, Bello MJ, Alonso J, Leone PE, Vaquero J, Sarasa JL, et al: Search for mutations of the hRAD54 gene in sporadic meningiomas with deletion at 1p32. Mol Carcinog 24:300-304, 1999

61. Mérel P, Hoang-Xuan K, Sanson M, Moreau-Aubry A, Bijlsma EK, Lazaro C, et al: Predominant occurrence of 
somatic mutations of the NF2 gene in meningiomas and schwannomas. Genes Chromosomes Cancer 13:211-216, 1995

62. Morrison H, Sperka T, Manent J, Giovannini M, Ponta H, Herrlich P: Merlin/neurofibromatosis type 2 suppresses growth by inhibiting the activation of Ras and Rac. Cancer Res 67:520-527, 2007

63. Niedermayer I, Feiden W, Henn W, Steilen-Gimbel H, Steudel WI, Zang KD: Loss of alkaline phosphatase activity in meningiomas: a rapid histochemical technique indicating progression-associated deletion of a putative tumor suppressor gene on the distal part of the short arm of chromosome 1. J Neuropathol Exp Neurol 56:879-886, 1997

64. Northcott PA, Korshunov A, Pfister SM, Taylor MD: The clinical implications of medulloblastoma subgroups. Nat Rev Neurol 8:340-351, 2012

65. Ostrom QT, Gittleman H, Farah P, Ondracek A, Chen Y, Wolinsky Y, et al: CBTRUS statistical report: Primary brain and central nervous system tumors diagnosed in the United States in 2006-2010. Neuro Oncol 15 (Suppl 2):ii1-ii56, 2013

66. Palma L, Celli P, Franco C, Cervoni L, Cantore G: Longterm prognosis for atypical and malignant meningiomas: a study of 71 surgical cases. Neurosurg Focus 2(4):e3, 1997

67. Palma L, Celli P, Franco C, Cervoni L, Cantore G: Longterm prognosis for atypical and malignant meningiomas: a study of 71 surgical cases. J Neurosurg 86:793-800, 1997

68. Perry A, Banerjee R, Lohse CM, Kleinschmidt-DeMasters BK, Scheithauer BW: A role for chromosome 9p21 deletions in the malignant progression of meningiomas and the prognosis of anaplastic meningiomas. Brain Pathol 12:183-190, 2002

69. Perry A, Louis DN, Scheithauer BW, Budka H, von Deimling A: Meningiomas, in Louis DN, Ohgaki H, Wiestler OD, et al (eds): WHO Classification of Tumours of the Central Nervous System, ed 4. Lyon, France: IARC, 2007, pp 164-172

70. Perry A, Scheithauer BW, Stafford SL, Lohse CM, Wollan PC: "Malignancy" in meningiomas: a clinicopathologic study of 116 patients, with grading implications. Cancer 85:2046-2056, 1999

71. Peters N, Wellenreuther R, Rollbrocker B, Hayashi Y, Meyer-Puttlitz B, Duerr EM, et al: Analysis of the PTEN gene in human meningiomas. Neuropathol Appl Neurobiol 24:3-8, 1998

72. Piaskowski S, Rieske P, Szybka M, Wozniak K, Bednarek A, Płuciennik E, et al: GADD45A and EPB41 as tumor suppressor genes in meningioma pathogenesis. Cancer Genet Cytogenet 162:63-67, 2005

73. Reifenberger J, Wolter M, Weber RG, Megahed M, Ruzicka $\mathrm{T}$, Lichter P, et al: Missense mutations in SMOH in sporadic basal cell carcinomas of the skin and primitive neuroectodermal tumors of the central nervous system. Cancer Res 58:1798-1803, 1998

74. Reuss DE, Piro RM, Jones DT, Simon M, Ketter R, Kool $\mathrm{M}$, et al: Secretory meningiomas are defined by combined KLF4 K409Q and TRAF7 mutations. Acta Neuropathol 125:351-358, 2013

75. Riant F, Bergametti F, Fournier HD, Chapon F, MichalakProvost S, Cecillon M, et al: CCM3 Mutations Are Associated with Early-Onset Cerebral Hemorrhage and Multiple Meningiomas. Mol Syndromol 4:165-172, 2013

76. Riemenschneider MJ, Perry A, Reifenberger G: Histological classification and molecular genetics of meningiomas. Lancet Neurol 5:1045-1054, 2006

77. Rogers L, Barani I, Chamberlain M, Kaley TJ, McDermott M, Raizer J, et al: Meningiomas: knowledge base, treatment outcomes, and uncertainties. A RANO review. J Neurosurg 122:4-23, 2015

78. Rong R, Tang X, Gutmann DH, Ye K: Neurofibromatosis 2
(NF2) tumor suppressor merlin inhibits phosphatidylinositol 3-kinase through binding to PIKE-L. Proc Natl Acad Sci U S A 101:18200-18205, 2004

79. Ruttledge MH, Sarrazin J, Rangaratnam S, Phelan CM, Twist E, Merel P, et al: Evidence for the complete inactivation of the NF2 gene in the majority of sporadic meningiomas. Nat Genet 6:180-184, 1994

80. Sahm F, Bissel J, Koelsche C, Schweizer L, Capper D, Reuss D, et al: AKT1E17K mutations cluster with meningothelial and transitional meningiomas and can be detected by SFRP1 immunohistochemistry. Acta Neuropathol 126:757-762, 2013

81. Sawyer JR, Husain M, Pravdenkova S, Krisht A, Al-Mefty $\mathrm{O}$ : A role for telomeric and centromeric instability in the progression of chromosome aberrations in meningioma patients. Cancer 88:440-453, 2000

82. Schmitz U, Mueller W, Weber M, Sévenet N, Delattre $\mathrm{O}$, von Deimling A: INI1 mutations in meningiomas at a potential hotspot in exon 9. Br J Cancer 84: 199-201, 2001

83. Sekulic A, Migden MR, Oro AE, Dirix L, Lewis KD, Hainsworth JD, et al: Efficacy and safety of vismodegib in advanced basal-cell carcinoma. N Engl J Med 366:21712179,2012

84. Simon M, Boström JP, Hartmann C: Molecular genetics of meningiomas: from basic research to potential clinical applications. Neurosurgery 60:787-798, 2007

85. Simon M, Park TW, Leuenroth S, Hans VH, Löning T, Schramm J: Telomerase activity and expression of the telomerase catalytic subunit, hTERT, in meningioma progression. J Neurosurg 92:832-840, 2000

86. Simpson D: The recurrence of intracranial meningiomas after surgical treatment. J Neurol Neurosurg Psychiatry 20:22-39, 1957

87. Smith MJ, O'Sullivan J, Bhaskar SS, Hadfield KD, Poke $\mathrm{G}$, Caird J, et al: Loss-of-function mutations in SMARCE1 cause an inherited disorder of multiple spinal meningiomas. Nat Genet 45:295-298, 2013

88. Smith MJ, Wallace AJ, Bennett C, Hasselblatt M, ElertDobkowska E, Evans LT, et al: Germline SMARCE1 mutations predispose to both spinal and cranial clear cell meningiomas. J Pathol 234:436-440, 2014

89. Sosman JA, Kim KB, Schuchter L, Gonzalez R, Pavlick AC, Weber JS, et al: Survival in BRAF V600-mutant advanced melanoma treated with vemurafenib. N Engl J Med 366:707-714, 2012

90. Steilen-Gimbel H, Niedermayer I, Feiden W, Freiler A, Steudel WI, Zang KD, et al: Unbalanced translocation $\mathrm{t}(1 ; 3)(\mathrm{p} 12-13 ; \mathrm{q} 11)$ in meningiomas as the unique feature of chordoid differentiation. Genes Chromosomes Cancer 26:270-272, 1999

91. Stott FJ, Bates S, James MC, McConnell BB, Starborg M, Brookes $\mathrm{S}$, et al: The alternative product from the human CDKN2A locus, p14(ARF), participates in a regulatory feedback loop with p53 and MDM2. EMBO J 17:50015014, 1998

92. Sun SQ, Cai C, Murphy RK, DeWees T, Dacey RG, Grubb $\mathrm{RL}$, et al: Management of atypical cranial meningiomas, part 2: predictors of progression and the role of adjuvant radiation after subtotal resection. Neurosurgery 75:356363,2014

93. Sun SQ, Kim AH, Cai C, Murphy RK, DeWees T, Sylvester $\mathrm{P}$, et al: Management of atypical cranial meningiomas, part 1: predictors of recurrence and the role of adjuvant radiation after gross total resection. Neurosurgery 75:347-355, 2014

94. Takahashi K, Tanabe K, Ohnuki M, Narita M, Ichisaka T, Tomoda K, et al: Induction of pluripotent stem cells from adult human fibroblasts by defined factors. Cell 131:861872,2007 
95. Tanzler E, Morris CG, Kirwan JM, Amdur RJ, Mendenhall WM: Outcomes of WHO Grade I meningiomas receiving definitive or postoperative radiotherapy. Int J Radiat Oncol Biol Phys 79:508-513, 2011

96. van Alkemade H, de Leau M, Dieleman EM, Kardaun JW, van Os R, Vandertop WP, et al: Impaired survival and longterm neurological problems in benign meningioma. Neuro Oncol 14:658-666, 2012

97. van den Munckhof P, Christiaans I, Kenter SB, Baas F, Hulsebos TJ: Germline SMARCB1 mutation predisposes to multiple meningiomas and schwannomas with preferential location of cranial meningiomas at the falx cerebri. Neurogenetics 13:1-7, 2012

98. Vernooij MW, Ikram MA, Tanghe HL, Vincent AJ, Hofman A, Krestin GP, et al: Incidental findings on brain MRI in the general population. N Engl J Med 357:1821-1828, 2007

99. Weber RG, Boström J, Wolter M, Baudis M, Collins VP, Reifenberger G, et al: Analysis of genomic alterations in benign, atypical, and anaplastic meningiomas: toward a genetic model of meningioma progression. Proc Natl Acad Sci U S A 94:14719-14724, 1997

100. Wen PY, Quant E, Drappatz J, Beroukhim R, Norden AD: Medical therapies for meningiomas. J Neurooncol 99:365378,2010

101. Witt H, Mack SC, Ryzhova M, Bender S, Sill M, Isserlin R, et al: Delineation of two clinically and molecularly distinct subgroups of posterior fossa ependymoma. Cancer Cell 20:143-157, 2011

102. Yang HW, Kim TM, Song SS, Shrinath N, Park R, Kalamarides M, et al: Alternative splicing of CHEK2 and codeletion with NF2 promote chromosomal instability in meningioma. Neoplasia 14:20-28, 2012

103. Yang SY, Park CK, Park SH, Kim DG, Chung YS, Jung HW: Atypical and anaplastic meningiomas: prognostic implications of clinicopathological features. J Neurol Neurosurg Psychiatry 79:574-580, 2008
104. Zhang X, Gejman R, Mahta A, Zhong Y, Rice KA, Zhou Y, et al: Maternally expressed gene 3, an imprinted noncoding RNA gene, is associated with meningioma pathogenesis and progression. Cancer Res 70:2350-2358, 2010

\section{Disclosures}

The authors report no conflict of interest concerning the materials or methods used in this study or the findings specified in this paper.

\section{Author Contributions}

Conception and design: IF Dunn, Bi. Acquisition of data: Bi. Analysis and interpretation of data: Bi, Brewster. Drafting the article: IF Dunn, Bi. Critically revising the article: IF Dunn, Bi, Abedalthagafi, Horowitz, Agarwalla, Mei, Aizer, GP Dunn, AlMefty, Alexander, Santagata, Beroukhim. Reviewed submitted version of manuscript: all authors. Approved the final version of the manuscript on behalf of all authors: IF Dunn, Bi. Study supervision: IF Dunn.

\section{Supplemental Information}

Current Affiliations

Dr. Abedalthagafi: Department of Pathology, King Fahad Medical City, and King Abdulaziz City for Science and Technology, Riyadh, Saudi Arabia.

\section{Correspondence}

Ian F. Dunn, Department of Neurosurgery, Brigham and Women’s Hospital, 15 Francis St., Boston, MA 02115. email: idunn@ partners.org. 